\title{
In vitro cytotoxicity and quantitative silica analysis of diatomaceous earth products
}

\author{
E BYE,' R DAVIES, ${ }^{2}$ D M GRIFFITHS, ${ }^{2}$ B GYLSETH,' AND C B MONCRIEFF ${ }^{2}$ \\ From the Institute of Occupational Health, ${ }^{1}$ Oslo, Norway, and the Pneumoconiosis Unit, ${ }^{2}$ Medical Research \\ Council, Penarth, S Glamorgan, UK
}

ABSTRACT Mouse peritoneal macrophages were used to evaluate the relative cytotoxicity of a series of diatomaceous earth products in vitro. The amorphous and crystalline silica content of the products was determined by a combination of infrared spectroscopy and $x$ ray powder diffraction techniques. The cytotoxicities of the high cristobalite content flux calcined materials were similar to that of the standard cristobalite; both the natural and straight calcined materials had significantly greater activities than the flux calcined materials. Thus within the limitations of the macrophage cytotoxicity test the hypothesis that crystalline content is the only determinant of fibrogenicity of diatomaceous earth is not supported.

Diatomaceous earth, Kieselguhr or diatomite, is a mineral found in several parts of the world which, after suitable treatment, may be used as a filler, as thermal insulation, as fine abrasive powder, and as an absorbant of liquids. The deposits of diatomaceous earth result from the death of diatoms (unicellular algae) over thousands of years in shallow bays or lakes where, as the organic material decomposes, their shells sink to the bottom and are compressed by subsequent sediments. The diatoms have an amorphous silica shell, a portion of which on calcining can be converted to the crystalline silica cristobalite, which exceeds $50 \%$ of some flux calcined products.

Workers may be exposed to natural and calcined forms of diatomite. The way the diatomite is calcined (straight or with a flux) results in qualitative differences in the structural forms of the diatomite silica. These differences are considered to be important for the development of pneumoconiosis. Indeed, according to Parkes "the severity [of this uncommon pneumoconiosis] appears to correlate with the cristobalite content of the dust and the duration of the exposure." Before discussing the known biological effects of diatomite, a review of the biological effects of various silica polymorphs may be worth while.

The naturally occurring crystalline silica quartz can cause silicosis and its presence in the dust from flint, sandstone, granite, and slate is probably

Received 4 January 1983

Accepted 29 March 1983 responsible for the pneumoconiosis associated with the use of these minerals. The crystalline silicas quartz, cristobalite, tridymite, ${ }^{2}$ and coesite $^{3}$ cause pulmonary fibrosis in experimental animal studies but stishovite does not. ${ }^{4}$

An extensive range of synthetic amorphous silicas is manufactured, only a few of which have been studied for their biological effects. No pneumoconiosis was found among workers exposed to precipitated ${ }^{56}$ or fumed silica ${ }^{7}$ but evidence of pulmonary fibrosis ${ }^{8}$ was found in workers exposed to amorphous silica dust produced as a byproduct of silicon metal production. In this process quartz is vaporised in an electric arc furnace but $x$ ray diffraction studies have indicated the presence of crystalline silica in the dust. Recently, Brambilla et al suggested that pneumoconiosis in a silicon factory was due to amorphous silica particles. ${ }^{9}$

Experimental animal studies with fumed silicas 1011 indicated that these materials caused some tissue reaction but there was no progression to collagen formation. Similar findings were made with a precipitated silica in animal inhalation studies. ${ }^{12}$ Groth et al,$^{13}$ however, found early nodular fibrosis in the lungs of monkeys exposed to fumed silica and vitreous silica-that is, fused silica or quartz glass has also been found to be fibrogenic ${ }^{14}$ but less so than quartz. ${ }^{21}$

In a major $x$ ray investigation of diatomaceous - earth workers, Cooper and Cralley found that $9 \%$ had lung changes interpreted as pneumoconiosis and that an equal number had doubtful changes. ${ }^{15}$ The 
prevalence of abnormal chest films was especially high in employees in the mills, where the dust contained a high percentage of cristobalite. Exposure in the quarries was associated with a lower proportion of abnormal films, none of 25 employees who had worked there exclusively for over five years had a positive film but $40 \%$ showed doubtful linear nodular changes. The dust in the quarries was essentially amorphous silica, the quartz content of the crude diatomite being $2 \%$. The authors pointed out that this evidence is in agreement with earlier observations indicating that the risk of pneumoconiosis is relatively low in workers whose exposure is confined to crude diatomite as compared with those exposed to calcined material. Nevertheless, it may be unwarranted to regard the natural material as innocuous as the dust concentrations in the quarries were not necessarily of the same order of magnitude as those in the mill. Franzinelli et al have made similar observations. ${ }^{16}$ Beskow and Omura et al have also reported cases of diatomaceous earth pneumoconiosis but the exact nature of the dust was not indicated. 1718

In experimental animal studies Tebbens and Beard found that inhalation of raw natural diatomaceous earth (containing no detectable crystalline silica) produced no fibrosis in guinea pigs ${ }^{19}$ and Swensson found that intratracheal injections of Kieselguhr into rats had an appreciably less pronounced reaction than quartz. ${ }^{11}$ A heated Kieselguhr $\left(800^{\circ} \mathrm{C}\right.$ for 24 hours), however, produced a stronger tissue reaction than the natural Kieselguhr material, although $x$ ray diffraction showed the absence of crystalline silica in both materials. A similar result was obtained by Klosterkötter ${ }^{10}$ using fumed silica. This material caused some tissue reaction after intratracheal instillation but after being heated for eight hours at $800^{\circ} \mathrm{C}$, while still amorphous (by $x$ ray diffraction), it was highly fibrogenic.

Wagner et al in an inhalation study using calcined diatomaceous earth (containing $61 \%$ cristobalite) found no parenchymal fibrosis in rats or guinea pigs but some hyalinised fibrotic nodules in the hilar lymph nodes of dogs. ${ }^{20}$

Few in vitro studies have been conducted on diatomaceous earths. Dusts cytotoxic towards macrophages in vitro usually cause fibrosis in animal studies $^{21-23}$; thus the crystalline silicas quartz, tridymite, and cristobalite are cytotoxic. ${ }^{21}$ Davies found that several synthetic amorphous silicas were cytotoxic towards macrophages. ${ }^{24}$ Their (general) lack of fibrogenicity in animal studies may be due in part to synthetic amorphous silicas being eliminated from the lung more readily than quartz..$^{25}$

Since the factors determining the biological effects of diatomite are unclear, we examined their cytotoxicity towards macrophages in vitro. As the composition of diatomite may be critical, it was considered essential to characterise the materials under study by $x$ ray diffraction and infrared spectroscopic analysis given the changes in composition that arise during various calcining processes.

\section{Materials and methods}

\section{MINERAL DUSTS}

Standard cristobalite was supplied by Arbetarskyddsstyrelsen, Stockholm, Swedęn. The material is prepared by heating $\alpha$-quartz (Fyle quartz) and a suitably fine fraction $(<5 \mu \mathrm{m})$ obtained by sedimentation. DQ12 standard quartz ${ }^{26}$ was supplied by the Institute of Occupational Medicine, Edinburgh, and magnetite from BDH Chemicals Ltd, Poole, Dorset.

Seven diatomaceous earth products (B-H in the table) were examined. The natural material, the crude diatomaceous earth, would have been dried at temperatures between 150 and $400^{\circ} \mathrm{C}$, the calcined material heated to $870-1100^{\circ} \mathrm{C}$, and the flux calcined material prepared by mixing the crude material with a flux, usually disodium carbonate, and heating to about $1100^{\circ} \mathrm{C} .{ }^{15}$ Suitable fine fractions were obtained by sedimentation in distilled water. The

Silica content and biological activity. The amount of silica is determined by combined infrared spectroscopy and $x$ ray diffraction, and the biological activity is evaluated as dust cytotoxicity towards mouse peritoneal macrophages

\begin{tabular}{|c|c|c|c|c|c|c|c|c|}
\hline \multirow[t]{2}{*}{ Code } & \multirow[t]{2}{*}{ Name } & \multirow[t]{2}{*}{ Type* } & \multirow[t]{2}{*}{$\begin{array}{l}\alpha \text {-Quartz } \\
(\%)\end{array}$} & \multirow[t]{2}{*}{$\begin{array}{l}\text { Cristobalite } \\
(\%)\end{array}$} & \multirow[t]{2}{*}{$\underset{(\%)}{\text { Amorphous } \mathrm{SiO}_{2}}$} & \multicolumn{3}{|c|}{$\begin{array}{l}\text { Relative biological } \\
\text { activity } \dagger\end{array}$} \\
\hline & & & & & & Estimate & $95 \% 1$ & \\
\hline $\begin{array}{l}\text { A } \\
\text { B } \\
\text { C } \\
\text { D } \\
\text { E } \\
\text { F } \\
\text { G } \\
\text { H }\end{array}$ & $\begin{array}{l}\text { Cristobalite } \\
\text { Damolin GM-1 } \\
\text { Filter Cel } \\
\text { Damolin KM-W } \\
\text { Standard Super Cel } \\
\text { Ceca Clarcel CBL/2 } \\
\text { Dicalite White Filler } \\
\text { Ceca Clarcel DIV/2 }\end{array}$ & $\begin{array}{l}\mathbf{n} \\
\mathbf{n} \\
\mathbf{c} \\
\mathbf{c} \\
\mathbf{c} \\
\mathbf{f} \\
\mathbf{f}\end{array}$ & $\begin{array}{l}0 \\
2.7 \\
1.0 \\
2.4 \\
0.9 \\
0.7 \\
<0.5 \\
<0.5\end{array}$ & $\begin{array}{r}100 \\
0 \\
0 \\
0 \\
6 \\
11 \\
77 \\
85\end{array}$ & $\begin{array}{r}0 \\
45 \\
109 \\
72 \\
100 \\
94 \\
15 \\
0\end{array}$ & $\begin{array}{l}0 \cdot 13 \\
0.20 \\
0 \cdot 55 \\
0.16 \\
0 \cdot 18 \\
0 \cdot 59 \\
0 \cdot 13 \\
0 \cdot 11\end{array}$ & $\begin{array}{l}0 \cdot 12 \\
0 \cdot 19 \\
0 \cdot 50 \\
0 \cdot 15 \\
0 \cdot 16 \\
0 \cdot 54 \\
0 \cdot 12 \\
0 \cdot 10\end{array}$ & $\begin{array}{l}0 \cdot 15 \\
0 \cdot 22 \\
0 \cdot 61 \\
0 \cdot 18 \\
0 \cdot 19 \\
0 \cdot 64 \\
0 \cdot 14 \\
0 \cdot 12\end{array}$ \\
\hline
\end{tabular}

${ }^{*} \mathrm{n}=$ Natural; $\mathrm{c}=$ Calcined; $\mathbf{f}=$ Flux calcined.

+ Dilution factors, on this scale - DQ12 quartz $=1.00$ and magnetite $=0.02(0.00-0.04)$. 
samples examined are representative of commercially available products.

\section{DUST CHARACTERISATION}

The samples were examined by transmission electron microscopy. Quantitative assessment of the silica content was carried out by a combination of infrared spectroscopy and $x$ ray powder diffraction. ${ }^{27}$ Infrared analyses were carried out using a JASCO IR-A2 spectrometer and the potassium bromide disc procedure. Diffractometric measurements were carried out with a Philips diffractometer equipped with a broad focus copper anode $x$ ray tube and a graphite crystal monochromator.

The infrared techniques provide information of the total silica content by integration with $10 \mathrm{~cm}^{-1}$ intervals of the silica absorption region at $700-900$ $\mathrm{cm}^{-1}$. The $x$ ray diffraction technique yields the crystalline silica content. One milligram samples are suspended in water and filtrated with Nuclepore filters (pore size $0.8 \mu \mathrm{m}$ ). A diffraction line from a silver filter placed under the Nuclepore filter in the sample holder is used as an external standard for absorption correction..$^{28}$ The amorphous silica content may be obtained by subtraction of the crystalline component from the total silica content. The corresponding calibration constants for the materials are established with Fyle quartz and our laboratory standards of cristobalite and Kieselguhr.

\section{CULTURE OF MACROPHAGES WITH DUSTS}

Unstimulated mouse peritoneal macrophages were obtained by lavage of $22-27 \mathrm{~g}$ female TO mice (Tuck and Son Ltd, Battlesbridge, Essex) with three ml Medium 199 (Flow Laboratories, Irvine, Scotland) containing 5 IU heparin, $100 \mathrm{U}$ benzylpenicillin, and $100 \mu \mathrm{g}$ streptomycin/ml. Approximately 1.2 $\times 10^{6}$ cells (in $2 \mathrm{~cm}^{3}$ of the medium) were added to each well of Linbro tissue culture multi-well plates (Flow Laboratories, Irvine, well diameter of $24 \mathrm{~mm}$ ), and left for one hour at $37^{\circ} \mathrm{C}$ in a $5 \%$ $\mathrm{CO}_{2} / 95 \%$ air atmosphere.

At the end of the period the non-adherent cells were removed by washing with phosphate buffered saline (PBS) and $2 \mathrm{ml}$ Medium 199 containing the antibiotics and $10 \%$ newborn calf serum (Flow Laboratories, Irvine) was added. This serum had previously been heat inactivated $\left(56^{\circ} \mathrm{C}\right.$ for 30 minutes) and acid treated. ${ }^{29}$ Cultures were then left for 24 hours at $37^{\circ} \mathrm{C}$ in a $5 \% \mathrm{CO}_{2} / 95 \%$ air atmosphere before the addition of fresh dust containing medium.

Stock dust solutions were made up in PBS at approximate concentrations, ultrasonication being used to disperse the dust. The dust was added to the medium containing $10 \%$ serum at various concen- trations (see results) and left for two to three hours at $37^{\circ} \mathrm{C}$ before being added to the macrophage cultures. Two ml "dusted" medium were added to each of three culture dishes that were then incubated for another 18 hours.

At the end of this period the medium was collected and the adherent cells disrupted by the addition of $2 \mathrm{ml}$ saline containing $0.1 \%$ Triton X100 and $0.1 \%$ bovine serum albumin, and by rubbing the dish with a sterile siliconised rubber bung. Both medium and cell lysates were centrifuged at $500 \mathrm{~g}$ for 10 minutes and the supernatants assayed for lactate dehydrogenase (LDH) by a continous flow fluorimetric method ${ }^{30}$ using a Perkin Elmer model 3000 fluorescence spectrometer.

The release of LDH from the cells into the culture medium is an indicator of dust cytotoxicity and is calculated as:

$\%$ enzyme released into culture medium $=$

$$
\frac{\mathrm{M}}{\mathrm{M}+\mathrm{C}} \times 100
$$

where $\mathbf{M}=$ enzyme activity of medium and $\mathrm{C}=$ enzyme activity of cell lysate.

\section{ANALYSIS OF RESULTS}

It is supposed that each mineral acts as a dilution of quartz and the factor relating the concentration of quartz equivalent to a concentration of a mineral is called the dilution factor. These factors were estimated by calculating regression equations for $M$ / $(\mathrm{M}+\mathrm{C})$ in terms of dose with the common constraint that the effects should be identical at zero concentration; $95 \%$ confidence limits were obtained using Fieller's theorem. The dilution factors so obtained are mutually dependent through their common use of the estimated slope for quartz and the common intercept.

\section{Results}

\section{DUST MORPHOLOGY}

Figure 1 shows transmission electron micrographs of standard cristobalite and the seven diatomaceous earth materials under study. The samples are not respirable fractions but each contains a high proportion of materials less than $10 \mu \mathrm{m}$ in diameter. The particles present in the diatomaceous earth samples have a wide variety of shapes consisting of fragments of diatom skeletons, the flux calcined samples ( $G$, $\mathrm{H})$ having an altered appearance.

\section{SILICA CONTENT}

Figure 2 shows that the infrared absorption of the amorphous and crystalline silica overlap almost completely at $800 \mathrm{~cm}^{-1}$. Typical $x$ ray powder dif- 


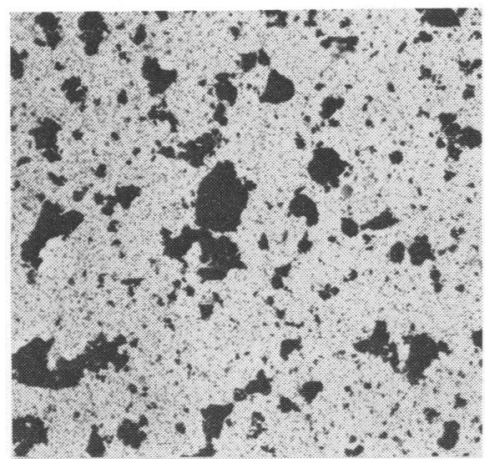

(A)

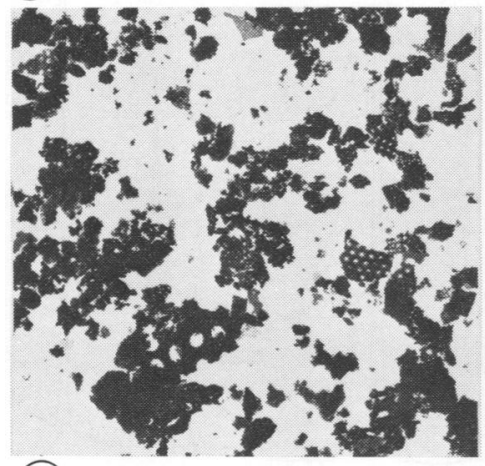

(D)

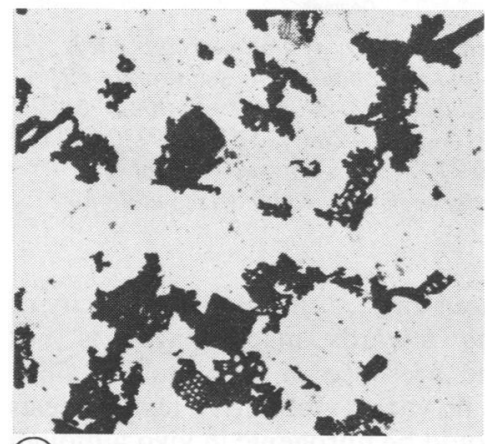

(G)

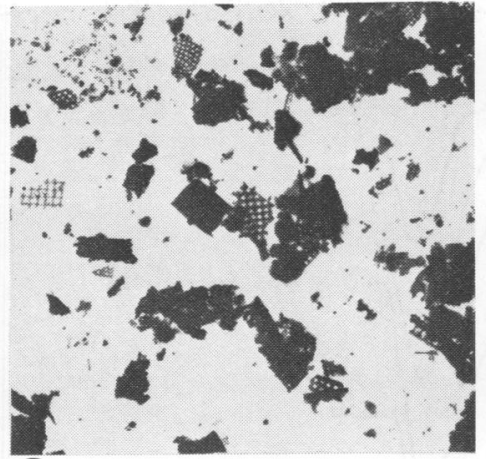

(B)

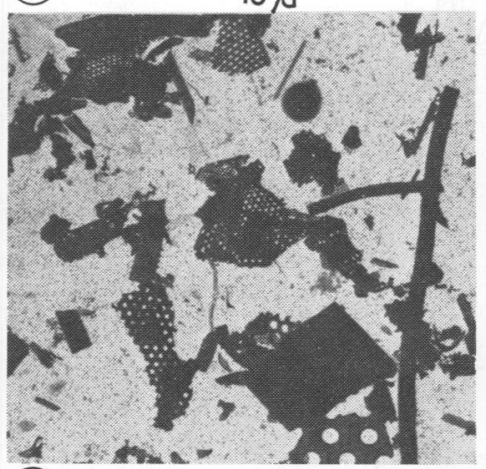

(E)

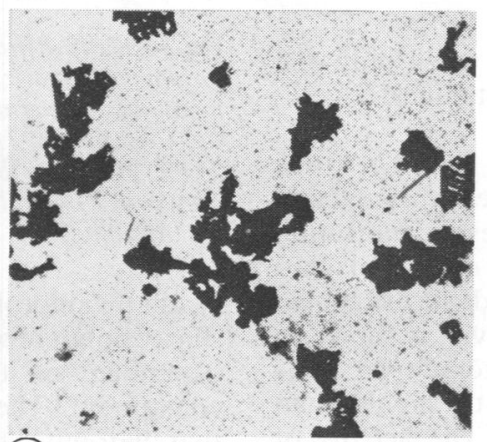

(H)

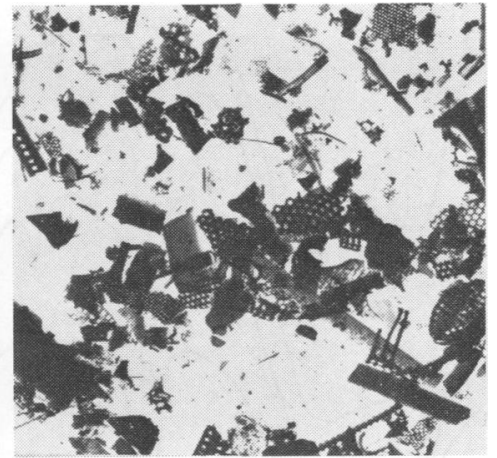

(C)

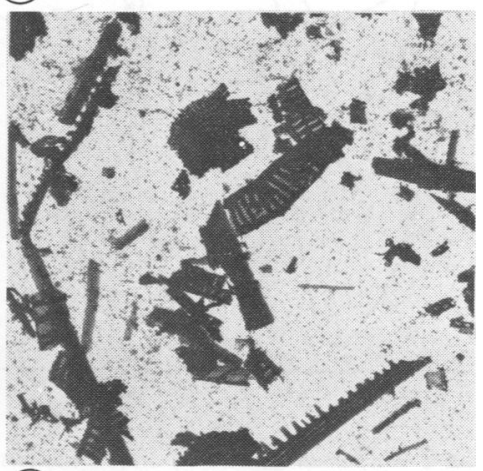

(F)

Fig 1 Transmission electron micrographs of diatomite materials. $A-$ cristobalite; $B-H-$ diatomite (see table for identification).

fraction patterns are shown in fig 3 ; the infrared and $x$ ray diffraction spectra of the other corresponding products are similar. The $\alpha$-quartz content of the diatomaceous earth matèrials was low (table). No cristobalite was found in the natural uncalcined material or in one of the calcined materials (D) which had been heated up to $650^{\circ} \mathrm{C}$. In the calcined materials (F \& E) $11 \%$ and $6 \%$ cristobalite was pre- sent and the flux calcined materials $(\mathrm{G} \& \mathrm{H})$ contained $77 \%$ and $85 \%$ cristobalite, respectively. Both the natural and calcined materials contain amorphous silica, which is significantly reduced in the flux calcined materials. It will be seen from the table that the total silica content of some samples is significantly above $100 \%$. This is mainly due to variations in material properties, such as particle size, 


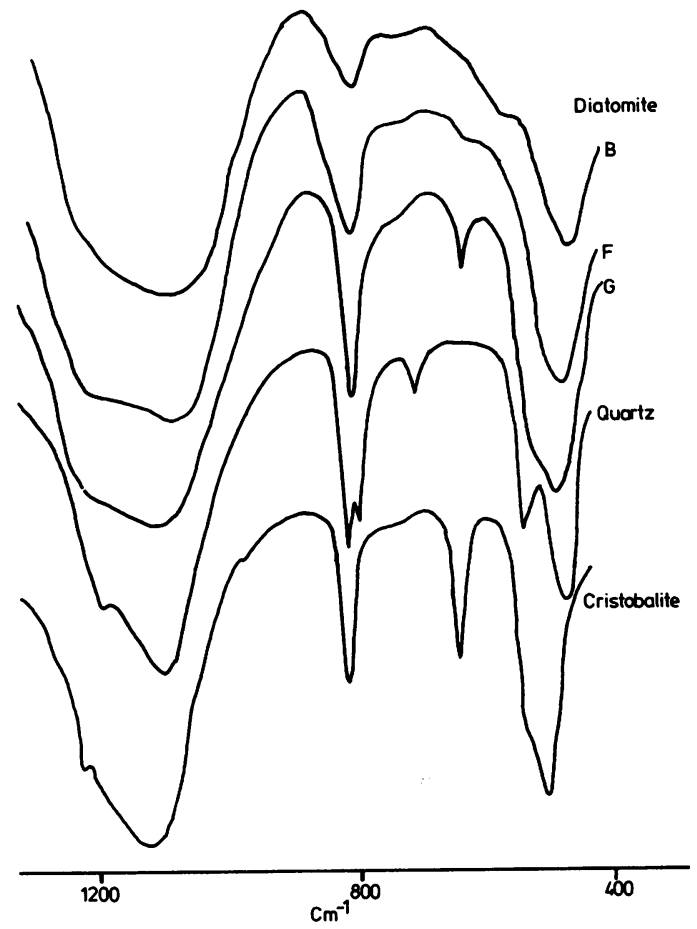

Fig 2 Infrared spectra of diatomaceous earth, $\alpha$-quartz, and cristobalite. Block letters refer to products (see table for identification).

between different mineral qualities when only one Kieselguhr is used as a calibration standard.

\section{MACROPHAGE CYTOTOXICITY}

The release of the cytoplasmic enzyme lactate dehydrogenase from the macrophages (an indication of cytotoxicity) after treatment with quartz, magnetite, and the diatomaceous earth products are shown in fig 4; their relative biological activity is shown in the table. The activities of the diatomite products are dose related and are significantly higher than magnetite, a non-fibrogenic ${ }^{31}$ dust. The activity of two samples (C,F) was high, about $50 \%$ of the activity of standard DQ12 quartz, which is one of the most cytotoxic of standard quartzes. ${ }^{32}$

The activities of the high cristobalite flux calcined materials $(G, H)$ were similar to the standard cristobalite (A). Both the natural and calcined materials had significantly greater activities than the flux calcined materials but this was not related to the quantity of crystalline or amorphous silica present.

\section{Discussion}

It is clear from this work, and an earlier study on

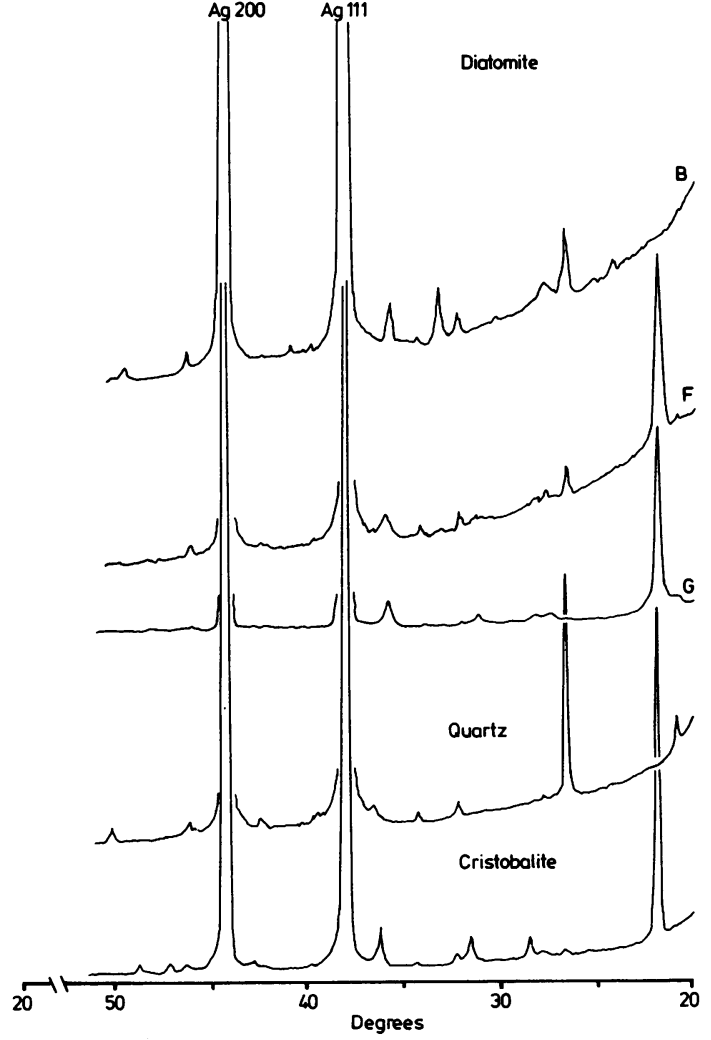

Fig $3 X$ ray diffraction pattern of diatomaceous earth products, $\alpha$-quartz, and cristobalite. The scan range for quantitative determinations are: $\alpha$-quartz: $26 \cdot 00-27 \cdot 68,2 \theta$ $\left({ }^{\circ}\right)$; Cristobalite: $21 \cdot 10-22 \cdot 76,2 \theta\left({ }^{\circ}\right)$; Silver: $37 \cdot 20-38 \cdot 87$, $2 \theta\left({ }^{\circ}\right)$. The silver line $(111)$ is used as an external. standard. ${ }^{27}$ Block letters refer to products (see table for identification).

synthetic amorphous silica, ${ }^{24}$ that the cytotoxicity of silica polymorphs towards macrophages is not dependent on the presence of a crystalline silica component. The in vitro cytotoxicity test suggests that diatomite should be fibrogenic in vivo although no fibrosis was reported in the one published study. ${ }^{18}$ Possibly amorphous silicas are a group of materials that give positive results with the in vitro technique applied in the present study, but may have low or no fibrogenicity in vivo. More animal inhalation data seems necessary to clarify this issue.

Swensson and Klosterkötter found fibrogenic effect with certain heated amorphous silicas which did not contain any crystalline components, ${ }^{1011}$ and it would be useful to evaluate the changes that amorphous silicas undergo during heating.

No explanation can be given for the cytotoxic effects of the diatomite products but it is possible 

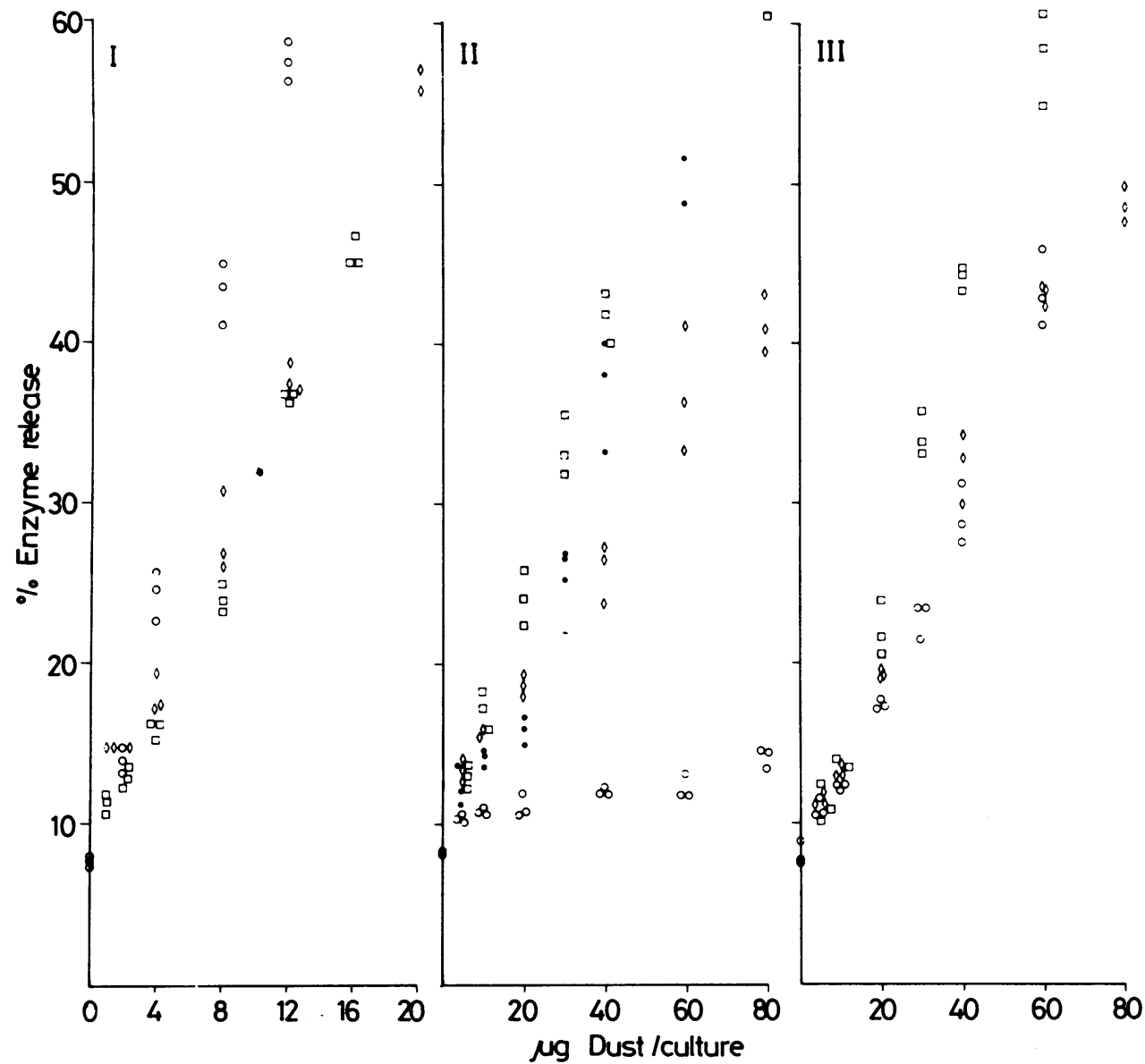

Fig 4 Effect of dusts on \% enzyme release from macrophages. I: Quartz $\bigcirc$ Product $C \square$ Product $F \diamond$ II: Magnetite $O$ Product $H \diamond$ Product $D \bullet$ Product $E$

III: Cristobalite $\bigcirc$ Product $\mathrm{G} \diamond$ Product $B$

that the surface hydroxyl groups ${ }^{33}$ or surface charge $e^{34}$ could play a part in membrane disruption as has been suggested for quartz. The morphology of the particles could also play a part, some of the materials had fibrous particles and it has been shown that the cytotoxic effects of fibrous asbestos minerals are related to their morphology..$^{35}$

The lower biological activity of the flux calcined materials is not easily explained but could be related to alterations in particle morphology during the fluxing process or the effect the fluxing agent has on the surface properties of the mineral.

We thank Dr J C Wagner for reading and Mrs Rosemary Hill and Miss Anne Eide for typing the manuscript. Mrs Sissel Olaisen is gratefully acknowledged for excellent technical help.
Requests for reprints to: $\mathrm{Dr} \mathrm{E}$ Bye, Institute of Occupational Health, PO Box 8149 Dep, Oslo 1, Norway.

\section{References}

' Parkes WR. Occupational lung disorders. 2nd ed. London: Butterworth, 1982: 162 .

${ }^{2}$ King EJ, Mohanty GP, Harrison CV, Nagelschmidt G. The action of different forms of pure silica on the lungs of rats. $\mathrm{Br} J$ Ind Med 1953;10:9-17.

${ }^{3}$ Brieger H, Gross P. On the theory of silicosis. I. Coesite. Arch Environ Health 1966;13:38-43.

4 Brieger H, Gross P. On the theory of silicosis. III. Stishovite. Arch Environ Health 1967;15:751-7.

s Plunkett ER, Dewitt BS. Occupational exposure to Hi-Sil and Silene. Arch Environ Health 1962;5:469-72.

- Wilson RK, Stevens PM, Lovejoy HB, Bell ZG, Richie RC. Respiratory effects of inhaled amorphous silica. In: Dunnom DD, ed. Health effects of synthetic silica particulates. American 
Society for Testing and Materials, 1981:185-98. (ASTM STP 732.)

7 Volk H. The health of workers in a plant making highly dispersed silica. Arch Environ Health 1960;1:125-8.

${ }^{8}$ Vitums VC, Edwards MJ, Niles NR, Borman JO, Lowry RD. Pulmonary fibrosis from amorphous silica dust. A product of silica vapor. Arch Environ Health 1977;32:62-8.

9 Brambilla C, Brambilla E, Rigaud D, Perdrix A, Paramelle B, Fourcy A. Pneumoconiose aux fumées de silice amorphe. Rev Fr Mal Respir 1980;8:383-91.

${ }^{10}$ Klosterkötter W. Zur Frage der silikogenen Wirkung des amorphen Silizium Dioxyds. Die Staublungener Krankungen 1958;3:236-47.

"Swensson A. Tissue reaction to different types of amorphous silica. In: Davies CN, ed. Inhaled particles and vapours. Vol 2. Oxford: Pergamon Press, 1967:95-102.

${ }^{12}$ Schepers GWH, Durkan TM, Delahant AB, Credon FT, Redlin AJ. The biological action of degussa submicron amorphous silica dusts. (Dow Corning silica). Arch Ind Health 1957;16: 125-46.

${ }^{13}$ Groth DH, Moorman WJ, Lynch DW, Stettler LE, Wagner WD, Hornung RW. Chronic effects of inhaled amorphous silicas in animals. In: Dunnom DD, ed. Health effects of synthetic silica particulates. 1981. American Society for Testing and Materials, 1981:118-43. (ASTM STP 732.)

${ }^{14}$ Brieger H, Gross P. On the theory of silicosis. II. Quartz glass. Arch Environ Health 1967;14:299-303.

is Cooper WC, Cralley LJ. Pneumoconiosis in diatomite mining and processing. Washington: US Government Printing Office, 1958. (Public Health Service Publication No 601.)

${ }^{16}$ Franzinelli A, Sartorelli E, Lomartire N, and Carini R. A contribution to the study of fossil flour pneumoconiosis. Med Lav 1971;62:258-71.

${ }^{17}$ Beskow R. Silicosis in diatomaceous earth factory workers in Sweden. Scand J Respir Dis 1978;59:216-21.

${ }^{18}$ Omura T, Nakagawa H, Yamamoto S, Kato T, Honda R, Nogawa K. Respiratory function abnormalities in workers exposed to diatomaceous earth dust. Jap $J$ Ind Health 1978;20:254-60.

${ }^{19}$ Tebbens BD, Beard RR. Experiments on diatomaceous earth pneumoconiosis. Archives of Industrial Health 1957;16:55-63.

${ }^{20}$ Wagner WD, Fraser DA, Wright PG, Dobrogorski OJ, Stokinger HE. Experimental evaluation of the threshold limit of cristobalite - calcined diatomaceous earth. Am Ind Hyg Assoc J 1968;29:211-21.
21 Marks J, Nagelschmidt G. Study of the toxicity of dust in use of the in vitro dehydrogenase techniques. AMA Arch Ind Health 1959;20:383-9.

${ }^{22}$ Styles JA, Wilson J. Comparison between in vitro toxicity of polymer and mineral dusts and their fibrogenicity. Ann Occup Hyg 1973;16:241-50.

${ }^{23}$ Miller K, Harington GS. Some biological effects of asbestos on macrophages. Br J Exp Pathol 1972;53:397-405.

${ }^{24}$ Davies R. Effects of synthetic silicas on mouse peritoneal macrophages in vitro. In: Dunnom DD, ed. Health effects of synthetic silica particulates. American Society for Testing and Materials, 1981:67-81. (ASTM STP 732.)

${ }^{25}$ Klosterkötter W, Bünemann G. Animal experiments on the elimination of inhaled dust. In: Davies $\mathrm{CN}$, ed. Inhaled particles and vapours. Oxford: Pergamon Press, 1961:327-41.

${ }^{26}$ Robock K. Standard quartz DQ12 $<5 \mu \mathrm{m}$ for experimental pneumoconiosis research projects in the Federal Republic of Germany. Ann Occup Hyg 1973;16:63-6.

${ }^{27}$ Bye E, Edholm G, Gylseth B, Nicholson DN. On the determination of crystalline silica in the presence of amorphous silica. Ann Occup Hyg 1980;23:329-34.

${ }^{28}$ Bye E. Quantitative microanalysis of cristobalite by $x$ ray powder diffraction. Journal of Applied Crystallography 1983; 16:21-3.

${ }^{29}$ Gordon S, Werb Z, Cohn ZA. In: Bloom BR, David JR, eds. In vitro methods in cell mediated and tumour immunity. London: Academic Press, 1976:344.

${ }^{30}$ Morgan DML, Vint S, Rideout JM. Continuous flow fluorimetric assay of lysosomal enzymes. Med Lab Sci 1978;35:335-41.

${ }^{31}$ Davis JMG. The fibrogenic effects of mineral dusts injected into the pleural cavity of mice. Br J Exp Pathol 1972;53:190-201.

${ }^{32}$ Wagner MMF, Wagner JC, Davies R, Griffiths DM. Silicainduced malignant histiocytic lymphoma. Incidence linked with strain of rat and type of silica. Br J Cancer 1980;41:90817.

${ }^{33}$ Nash T, Allison AC, Harington JS. Physico-chemical properties of silica in relation to its toxcity. Nature 1966;210:259-61.

${ }^{34}$ Nolan RP, Langer AM, Harington JS, Oster G, Selikoff LJ. Quartz hemolysis as related to its surface functionalities. Environ Res 1981;26: 503-20.

${ }^{35}$ Davies R, Chamberlain M, Brown RC, Griffiths DM. Identification of toxic mineral dusts using mammalian cells. Transactions of the Royal Society of Edinburgh Earth Sciences 1980;71:181-4. 